\title{
INFLUENNCIA DAS FORMAS DE CARBOIDRATOS NO TREINAMENTO FÍSICO E NA SUPERCOMPENSAÇÃO GLICOGÊNICA DE RATOS ${ }^{1}$
}

\author{
HESSEL MARANI LIMA ${ }^{1}$ \\ MARIA DE FÁTIMA PÍCCOLO BARCELOS ${ }^{2}$ \\ RAIMUNDO VICENTE DE SOUSA ${ }^{3}$ \\ AUGUSTO RAMALHO DE MORAIS ${ }^{4}$
}

\begin{abstract}
RESUMO - Foram utilizadas duas formas de carboidratos, sacarose e amido de milho no treinamento físico de ratos, tendo como base o método "clássico" de supercompensação de glicogênio, que inclui a depleção de glicogênio tecidual seguido pela carga de carboidratos. Os parâmetros analisados foram: ganho de peso corporal, conversão alimentar, eficiência alimentar, níveis teciduais de glicogênio muscular e hepático, glicose plasmática e lipídios totais séricos. Foram utilizados ratos machos Wistar, que consumiram dietas com carboidrato simples (CHOs) e carboidrato complexo ( $\mathrm{CHOc})$. O experimento constituiu-se de três fases: $1^{\mathrm{a}}$ Fase-adaptação ao meio líquido; $2^{\mathrm{a}}$ Fasetreinamento, quando foi instalado o programa de treinamento físico. Nas Fases 1 e 2, os grupos receberam dietas contendo $75 \%$ de carboidratos e, finalmente, na 3 Fase de "supercompensação de glicogênio", fez-se uma alternância na concentração de carboidratos. Dando prosseguimento a essa fase, os grupos foram submetidos a um dia denominado "evento", quando todos os grupos de
\end{abstract}

animais nadaram por 2 h $30 \mathrm{~min}$. Ao término desse, foi monitorada a repleção dos depósitos teciduais de glicogênio nos seguintes tempos $0,6,12,24,48$ e 72 horas. Pelos principais resultados, verifica-se que: (a) o treinamento físico para ratos elevou os níveis teciduais de glicogênio; (b) as formas de CHO simples (sacarose) ou complexa (amido de milho) não interferiram no glicogênio tecidual, glicose plasmática e lipídios totais séricos); (c) a supercompensação de glicogênio promoveu armazenamento de glicogênio superior nos tecidos hepáticos dos ratos, quando comparados ao tecido muscular; (d) após exercício extenuante, a maior repleção de glicogênio em todos tecidos ocorreu com 12 horas, consumindo dietas com carboidratos simples ou complexos; (e) a forma complexa não proporcionou redução dos níveis de glicose sérica no pós-jejum de nove horas; (f) com o avançar do tempo, observou-se o aumento gradual dos teores dos lipídios totais, a cada hora, independentemente da forma de $\mathrm{CHO}$ consumida pelos animais.

TERMOS PARA INDEXAÇÃO: Formas de carboidrato, treinamento físico, supercompensação de glicogênio, glicogênio, ratos.

\section{INFLUENCE OF CARBOHYDRATES FORMS OF IN PHYSICAL TRAINING AND GLYCOGEN OVERCOMPENSATION IN RATS}

\begin{abstract}
Two carbohydrates forms, sucrose and corn starch, were utilized, in the physical training of rats, having as basis the "classic" method of overcompensation of glycogen which includes the depletion of tissue glycogen followed by carbohydrate load. The analyzed parameters were body weight gain, feed conversion, feed efficiency, tissue muscle and hepatic glycogen levels, plasma glucose and serum total
\end{abstract}

lipids. Wistar male rats were utilized, consuming diets with simples carbohydrates (CHOs) and complex carbohydrates $(\mathrm{CHOc})$. The experiment consisted of three phases: $1^{\text {st }}$ phase- adaptation to the liquid medium, $2^{\text {nd }}$ Phase- training, where the physical training program was established, in these phases 1 and 2 the groups were fed diets containing $75 \%$ of carbohydrates and finally in the $3^{\text {rd }}$ phase- of "glycogen

\footnotetext{
1. Trabalho extraído de parte da dissertação de mestrado em Ciência dos Alimentos do primeiro autor - UNIVERSIDADE FEDERAL DE LAVRAS/UFLA, Caixa Postal 37 - 37200-000 - Lavras, MG. hml.pandora@.com.br

2. Professora do Departamento de Ciência dos Alimentos, DCA/UFLA, piccolob@ufla.br

3. Professor do Departamento de Medicina Veterinária, DMV/UFLA.

4. Professor do Departamento de Ciência Exatas, DEX/UFLA.
} 
overcompensation", a shift in the concentration of carbohydrates was done. Proceeding this phase, the groups were submitted to one day called the "event", where all the groups swam for about 2 and a half hours and at the end of this, the replenishment of the tissue stores of glycogen in the following times 0,6 , 12, 24, 48 and 72 hours was monitored. The main results point out that: (a) the physical training for rats raised the tissue glycogen levels; (b) the forms of carbohydrates simple (sucrose) or complex (corn starch), did not intervene in tissue glycogen, plasma glucose and serum total lipids; (c) the overcompensation of glycogen rise higher store of glycogen in tissue hepatic rats as compared with tissue muscle; (d) the greatest replenishment of glycogen in all tissues occurred within 12 hours consuming diets with either simple or complex diets; (e) the complex form did not provide reduced levels of serum glucose in the 9-hour post-fasting; (f) With advancing time, the gradual increase of the contents of the total lipids every hour regardless of the form of $\mathrm{CHO}$ consumed by the animals.

INDEX TERMS: Forms of carbohydrates, physical training, overcompensation of glycogen, glycogen, rates.

\section{INTRODUÇÃO}

A supercompensação de glicogênio (carga) associada ao treinamento físico é utilizada, segundo Gollnick \& Saltin (1988), para maximizar os depósitos de carboidratos. A depleção do glicogênio muscular resulta num decréscimo das reservas energéticas durante o exercício, seguido pela cessação do mesmo. A supercompensação de glicogênio é indicada para atletas engajados num programa de exercício contínuo por mais de 90 a 120 minutos. O método "clássico" de supercompensação de carboidratos inclui a depleção de glicogênio tecidual, seguido pela carga do mesmo (Bergstrom et al., 1967).

Músculos depletados tornam-se supersaturados numa resposta proporcional à alta ingestão de carboidratos (500 a $600 \mathrm{~g} / \mathrm{dia})$ pelo indivíduo (Sherman, 1983). Esse método envolve uma fase de depleção de glicogênio por meio do exercício exaustivo e do consumo de uma dieta com baixo teor de carboidratos e, em seguida, uma fase de supercompensação na qual é consumida uma dieta muito rica em CHO ( $\square 90 \%$ do total de kcal) (Sherman \& Costill, 1984).

A carga de $\mathrm{CHO}$ permite aumentar o tempo de exercícios de alta intensidade, mas, normalmente, não influencia no rendimento na primeira hora de um evento (Coleman, 1991).

Quanto ao desempenho e fadiga, Coggan \& Coyle (1991) afirmam que o desempenho da resistência poderia ser melhorado pela ingestão de carboidratos, e Coyle (1992) informa que a alimentação à base de carboidratos não previne a fadiga durante o exercício de intensidade moderada, mas apenas a retarda por 30 a 60 $\min$.

Parece haver um limite superior para a intensidade do exercício prolongado ( $75 \%$ do $\mathrm{VO}_{2}$ máx.), que pode ser mantido com suplementação de carboidratos.
Não há dúvidas de que a supercompensação de carboidratos é um método eficiente para disponibilizar as reservas energéticas teciduais, tornando-se esse um efeito ergogênico. Em contrapartida, nem todos os estudos levam em consideração a forma de carboidrato administrada ou mesmo o tempo que cada uma dessas formas leva para restabelecer ou maximizar os depósito de glicogênio. Dessa forma, com o presente trabalho objetivou-se determinar o efeito de duas formas de carboidratos (sacarose e amido de milho) fornecidas a ratos treinados sobre a supercompensação de glicogênio, bem como verificar a relação da repleção de glicogênio teciduais em tempos pré-estabelecidos.

\section{MATERIAL E MÉTODOS}

O experimento foi conduzido nos Departamentos de Ciência dos Alimentos e Medicina Veterinária da Universidade Federal de Lavras, Lavras MG.

\section{Ensaio "in vivo"}

Foram utilizados 42 ratos Rattus norvegicus, machos da linhagem Wistar, com cerca de 45 dias de vida, pesando inicialmente, em média, $83 \pm 12 \mathrm{~g}$, provenientes do Instituto de Ciências Biológicas da Universidade Federal de Minas Gerais. Os animais foram mantidos em condições ambientais controladas, sob temperatura em $24^{\circ}$ a $28^{\circ} \mathrm{C}$ e períodos alternados de claro e escuro de 12 horas.

No decorrer do período pré-experimental (sete dias), os animais permaneceram divididos em gaiolas coletivas contendo, em média, 5 animais por gaiola, recebendo ração comercial (Nuvilab-CR1) e água ad libitum. $\mathrm{O}$ período pré-experimental foi para adequação dos animais ao manejo e ambiente. Após esse período, os animais foram pesados e distribuídos aleatoriamente com um animal por gaiola, sendo submetidos às três fa- 
ses do experimento: $1^{\mathrm{a}}$ Fase- adaptação ao meio líquido, com duração de 7 dias; $2{ }^{\text {a }}$ Fase- programa de treinamento de natação, com duração de 30 dias e, finalmente, a $3^{\mathrm{a}}$ Fase- programa de supercompensação de glicogênio muscular e hepático, com duração de 10 dias.

\section{Constituição dos tratamentos}

Trabalhou-se com dois tratamentos, com 21 animais em cada um. $\mathrm{O}$ primeiro tratamento com dieta à base de carboidrato simples (CHOs) e o segundo com dieta à base de carboidrato complexo (CHOc). Esses foram submetidos a sessões de treinamento (natação) a cada dois dias, considerando o mesociclo de treinamento pré-estabelecido, conforme Zakharov (1992).

\section{Programa de treinamento (natação)}

$\mathrm{O}$ treinamento foi realizado em tanques d'água de $75 \mathrm{~cm}$ de diâmetro por $55 \mathrm{~cm}$ de altura e capacidade 250 L. Tomou-se o cuidado de trocar a água a cada sessão de treinamento, no intuito de evitar contaminação por fezes e urina excretadas durante a sessão. Os animais foram separados dentro dos tanques por tubos de PVC-200 mm, sendo a água dentro desses mantida sob temperatura entre 29 $\pm 2^{\circ} \mathrm{C}$. A pelagem dos animais sempre foi seca após os períodos de natação. A duração do treinamento foi estabelecido em virtude de se evitar o envelhecimento do animal, o que poderia acarretar perda na adaptabilidade funcional do organismo diante do estímulo físico.

a) Natação - A natação foi escolhida pelo fato de essa ser uma modalidade bastante utilizada para área de estudo, com menor estresse emocional para o animal comparado aos exercícios em esteira rolante. As propriedades físico-químicas do meio líquido, que auxiliam o sistema cardiorespiratório e ósteoarticular, facilitando o retorno venoso e diminuindo o risco de lesões nas articulações, também apresentam uma regularidade na realização do esforço físico, elevando a estabilidade da homeostase e, conseqüentemente, menor comprometimento do experimento.

b) $\mathbf{1}^{\mathrm{a}}$ Fase (adaptação ao meio líquido) - Esta teve o intuito de minimizar a ocorrência de estresse intenso, em decorrência da água e da profundidade do tanque. Sessões progressivas de natação foram realizadas, e as atividades iniciaram com $15 \mathrm{~min}$, acrescendo-se a cada dia 5 min, até atingirem $30 \mathrm{~min}$, período que se estabilizaram e permaneceram até o final da $1^{\mathrm{a}}$ semana.

c) $2^{\mathrm{a}}$ Fase (treinamento) - $\mathrm{O}$ treinamento durou 4 semanas (natação entre 7 horas e 10 horas), de acordo com os micro e mesociclos: adaptativos, condicionantes e recuperativos, baseados na estrutura do treinamento, conforme Zakharov (1992), variando somente a duração de cada sessão de treinamento (volume de treinamento em horas) e havendo um intervalo de dois dias entre cada sessão de treinamento.

d) $3^{\circ}$ Fase ( supercompensação de glicogênio) Após o treinamento, os animais foram submetidos ao período de supercompensação de glicogênio por três dias, com dietas contendo teores de $40 \%$ de carboidratos seguidos por mais três dias com dietas a $90 \%$ de carboidratos. Durante esses dias, nenhum tipo de atividade física foi realizada; ao final desses seis dias, os animais foram submetidos a um dia denominado "evento", (natação por $2 \mathrm{~h} 30 \mathrm{~min}$. ininterruptas). Ao término do mesmo, as dietas foram novamente trocadas para teores de $75 \%$ de carboidratos e dois animais de cada grupo foram sacrificados nos seguintes tempos $0,6,12,24,48$ e 72 horas. Nessas 72 horas pós-evento, não se realizou nenhuma atividade física.

\section{Composição das dietas}

As dietas seguiram as especificações AIN-93 (American Institute of Nutrition) para ratos em crescimento (Reeves et al., 1993), com algumas modificações, apresentando-se isoenergéticas (Tabela 1). No período pré-experimental, utilizou-se ração comercial (NuvilabCR1); na $1^{\mathrm{a}}$ Fase e na $2^{\mathrm{a}}$ Fase, as dietas variaram apenas as formas de $\mathrm{CHO}$ (específicas por tratamento): utilizou-se sacarose como CHO-simples e o amido de milho como CHO-complexo, apresentando a seguinte distribuição de nutrientes: $75 \%$ de carboidratos, $12 \%$ de proteínas e 2,5\% de lipídios, mantendo a água e a alimentação ad libitum.

$\mathrm{Na} 3^{\mathrm{a}}$ Fase (supercompensação de glicogênio), para os três primeiros dias, alteraram-se as dietas para uma baixa porcentagem dos $\mathrm{CHO}: 40 \%$ de carboidratos, $30 \%$ de proteínas e $9 \%$ de lipídios. A esses três dias somaram-se mais três, com alta porcentagem de CHO, $90 \%$ de carboidratos, $0,4 \%$ de proteínas e $2 \%$ de lipídios. Nesses seis dias mantiveram-se os CHO específicos para cada tratamento. Após esses seis dias, os animais sofreram um dia de exaustão, e ao término desse, as dietas retornaram a $75 \%$ de carboidratos, $12 \%$ de proteínas e $2,5 \%$ de lipídios, até o final do experimento, sendo a água e a alimentação oferecidas ad libitum.

$\mathrm{Na}$ Tabela 1 encontram-se as dietas em suas respectivas fases experimentais. 
TABELA 1 - Distribuição dos componentes das dietas ${ }^{\mathrm{a}}$.

\begin{tabular}{|c|c|c|c|c|c|c|c|}
\hline \multicolumn{8}{|c|}{ Composição das dietas g /100g } \\
\hline \multirow{3}{*}{$\begin{array}{c}\text { Componentes } \\
\text { das dietas }\end{array}$} & \multirow{3}{*}{$\begin{array}{c}1^{\mathrm{a}} \text { Fase } \\
\text { CHO s/c } \\
75 \%\end{array}$} & \multicolumn{2}{|c|}{$2^{\mathrm{a}}$ Fase } & \multicolumn{4}{|c|}{$3^{\mathrm{a}}$ Fase } \\
\hline & & CHOs & CHOc & CHO s/c & CHO s/c & CHOs & СHOc \\
\hline & & $75 \%$ & $75 \%$ & $40 \%$ & $90 \%$ & $75 \%$ & $75 \%$ \\
\hline Dietas & A e B & $\mathrm{A}^{\prime}$ & $\mathrm{B}^{\prime}$ & C e D & E e F & $A^{\prime \prime}$ & $\mathrm{B}$, \\
\hline Caseína (proteína)* & 14,9 & 14,9 & 14,9 & 35 & 0,49 & 14,9 & 14,9 \\
\hline Óleo vegetal & 2,48 & 2,48 & 2,48 & 9 & 1,99 & 2,48 & 2,48 \\
\hline Sacarose CHOs** & A 74,6 & $A^{\prime} 74,6$ & - & $\mathrm{C} 40$ & E 89,5 & $A^{\prime \prime} 74,6$ & - \\
\hline Amido $\mathrm{CHOc}^{* * *}$ & B 74,6 & - & $B^{\prime} 74,6$ & D 40 & F 89,5 & - & B’’74,6 \\
\hline Mistura Vit. & 1 & 1 & 1 & 1 & 1 & 1 & 1 \\
\hline Mistura Min. & 3,5 & 3,5 & 3,5 & 3,5 & 3,5 & 3,5 & 3,5 \\
\hline Celulose & 3 & 3 & 3 & 3 & 3 & 3 & 3 \\
\hline Colina & 0,2 & 0,2 & 0,2 & 0,2 & 0,2 & 0,2 & 0,2 \\
\hline L - cistína & 0,3 & 0,3 & 0,3 & 0,3 & 0,3 & 0,3 & 0,3 \\
\hline BHT & 0,01 & 0,01 & 0,01 & 0,01 & 0,01 & 0,01 & 0,01 \\
\hline Vit- E & 0,01 & 0,01 & 0,01 & 0,01 & 0,01 & 0,01 & 0,01 \\
\hline q.s.p. & - & - & - & 7,98 & - & - & - \\
\hline Total em \% & 100 & 100 & 100 & 100 & 100 & 100 & 100 \\
\hline Total kcal & 367,9 & 367,9 & 367,9 & 352,6 & 377,4 & 367,9 & 367,9 \\
\hline
\end{tabular}

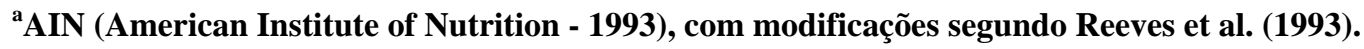

*Teor protéico da caseína $\mathbf{= 7 9 , 8 \%}$.

$* *$ CHOs $=$ carboidrato simples.

$* * *$ CHOc $=$ carboidrato complexo.

\section{Coleta das amostras}

a) Amostras sangüíneas - $\mathrm{Na} 1^{\mathrm{a}}$ e na $2^{\mathrm{a}}$ Fases do experimento, respectivamente cinco e quatro animais de cada tratamento tiveram dois dias de descanso. No terceiro dia, foram submetidos a 9 horas de jejum; logo após esse período, o sangue foi coletado por meio da decapitação da extremidade distal da cauda dos animais. No caso da glicose, fez-se o doseamento dos níveis glicêmicos também antes do período de jejum.

$\mathrm{Na} 3^{\mathrm{a}}$ Fase, tanto para o doseamento de glicose plasmática como de lipídios totais séricos, o sangue foi coletado nos tempos pré-estabelecidos $(0,6,12,48$ e 72 h) sem prévio jejum, seguindo os padrões utilizados nas análises da $1^{\mathrm{a}} \mathrm{e} 2^{\mathrm{a}}$ Fases.

b) Amostras teciduais - Como para o procedimento da coleta de amostras sanguíneas, no terceiro dia, foram sacrificados após jejum de 12 horas cinco e quatro animais referentes à $1^{\mathrm{a}}$ e $2^{\mathrm{a}}$ Fases do experimento. Realizou-se a laparotomia mediana, extraindo-se dois lóbulos hepáticos: Lateral direito e médio; e dois grupos musculares: músculos Sóleo e Gastrocnêmio das patas posteriores. As amostras foram imediatamente congeladas em nitrogênio líquido, evitando mudanças e degradações enzimáticas do conteúdo glicogênico, em virtude do rompimento celular provocado pelos cortes histoló- 
gicos. Em seguida, as amostras foram armazenadas em freezer para análises futuras.

Para a $3^{\text {a }}$ Fase, os mesmos tecidos foram coletados sem prévio jejum, sendo esses extraídos nos tempos $0,6,12,48$ e $72 \mathrm{~h}$, seguindo-se à mesma metodologia da $1^{\mathrm{a}}$ e $2^{\mathrm{a}}$ Fases.

\section{Parâmetros físicos e bioquímicos}

Determinação do ganho de peso corporal - Os animais foram pesados três vezes por semana. A determinação da média do peso corporal tem por base o peso (g) inicial e final de cada animal.

Determinação da conversão alimentar - A conversão alimentar foi obtida pelo consumo de dieta, em função do peso corporal, dividindo-se a quantidade do alimento ingerido $(\mathrm{g})$ pelo ganho de peso do animal $(\mathrm{g})$.

Determinação da eficiência alimentar - A eficiência alimentar foi calculada pela divisão do ganho de peso corporal do animal $(\mathrm{g})$ pelo total de alimento ingerido (g).

Glicogênio muscular e hepático - A determinação de glicogênio muscular e hepático foi realizada empregando-se o método colorimétrico, segundo Dubois et al. (1956).

Glicose sérica - Para determinação da glicose, utilizaram-se kits de glicose (Cat.34) da Labtest Diagnóstica, baseados no método enzimático (glicose oxidase), segundo Henry (1974).

Lipídios totais - Para a determinação da concentração de lipídios totais, foram utilizados kits de lipídios totais (Cat.15) da Labtest Diagnóstica, baseados no mé- todo colorimétrico (sulfofosfovanilina), segundo Henry (1974).

\section{Análises estatísticas}

$\mathrm{O}$ experimento foi conduzido segundo o delineamento experimental (inteiramente casualisado) DIC, em esquema fatorial 3 X 2 (Fases: 1, 2 e 3 / Formas de CHO: simples e complexa). A Fase 1 e a Fase 2 apresentaram 5 e 4 repetições, respectivamente; já a Fase 3 apresentou duas repetições para cada horário específico $(0,6,12,24,48$ e 72 horas), representando cada animal uma parcela experimental. Após a obtenção dos dados, esses foram submetidos a análises de variância ( $\mathrm{p} \leq$ $0,05)$, de acordo com os esquemas experimentais sugeridos por Gomes (1990), para experimentos fatoriais. Para realização das análises estatísticas, utilizaram-se dos pacotes estatísticos System Analysis Statistical (SAS INSTITUTE, 1993) e Sistema de Análise de Variância "Sisvar" (Ferreira, 2000)

\section{RESULTADOS E DISCUSSÃO}

\section{Ganho de peso corporal, conversão alimentar e eficiência alimentar}

Na Tabela 2 verificam-se o consumo alimentar (g), ganho de peso corporal (g), conversão alimentar, eficiência alimentar $(\%)$, valores médios do peso inicial e peso final (g) e média geral do peso corporal ( $\mathrm{g}$ ) no decorrer do período experimental.

TABELA 2 - Valores médios do consumo alimentar (g), ganho de peso corporal (g), conversão alimentar, eficiência alimentar $(\%)$, valores médios do peso inicial $(\mathrm{g})$ peso final $(\mathrm{g})$ e média geral do peso corporal $(\mathrm{g})$ no decorrer do período experimental.

\begin{tabular}{|c|c|c|c|c|c|c|c|}
\hline Tratamentos & $\begin{array}{c}\text { Consumo } \\
\text { Alimentar } \\
\text { (g) }\end{array}$ & $\begin{array}{c}\text { Ganho } \\
\text { de peso } \\
\text { (g) }\end{array}$ & $\begin{array}{l}\text { Conversão } \\
\text { Alimentar }\end{array}$ & $\begin{array}{c}\text { Eficiência } \\
\text { Alimentar } \\
(\%)\end{array}$ & $\begin{array}{c}\text { Peso } \\
\text { Inicial } \\
(\mathbf{g})\end{array}$ & \begin{tabular}{c}
\multicolumn{2}{c}{ Peso } \\
Final (g)
\end{tabular} & $\begin{array}{l}\text { Média geral do } \\
\text { peso corporal } \\
\text { (g) }\end{array}$ \\
\hline CHOs & $71,51^{\mathrm{a}}$ & $52,65^{\mathrm{a}}$ & $55,29^{\mathrm{a}}$ & $23,9^{\mathrm{a}}$ & 85,0 & 223,9 & $212,57^{\mathrm{a}}$ \\
\hline $\mathrm{CHOc}$ & $82,86^{\mathrm{a}}$ & $57,56^{\mathrm{a}}$ & $60,95^{\mathrm{a}}$ & $19,9^{\mathrm{a}}$ & 88,0 & 256,4 & $230,86^{b}$ \\
\hline Média & 77,18 & 55,11 & 58,12 & 21,9 & 86,5 & 440,1 & 222,00 \\
\hline C.V. $\%$ & 31,97 & 27,10 & 23,11 & 56,99 & - & - & 16,46 \\
\hline
\end{tabular}

Letras minúsculas nas coluna comparam os tratamentos. Valores seguidos de letras iguais não diferem pelo teste de Tukey a $5 \%$. 
De acordo com a Tabela 2, ao comparar os ganhos de peso corporal em função dos tratamentos, notase que não houve diferença significativa entre as mesmas. Mas, diante das médias de peso corporal, foram verificadas diferenças significativas, sendo a média geral da forma de carboidrato complexo $(230,86 \mathrm{~g})$ e a média geral da forma simples $(212,58 \mathrm{~g})$. Borchers e Butterfield, citados por Mahan \& Escott-Stump (1998), verificaram que, no período pós-atividade, a refeição deve ser rica em carboidratos complexos para manter a massa corporal magra. Pelas médias gerais do peso corporal, nota-se que o tratamento $\mathrm{CHOc}$ proporcionou maior peso corporal, motivo pelo qual provavelmente a massa corporal magra tenha contribuído para esses valores.

A diferença no ganho de peso entre as fases era um fato esperado. Isso porque os animais experimentais encontravam-se em plena fase de crescimento, o que vem confirmar que a alteração na composição das dietas, bem como mudanças no ciclo de vida diário (volume de atividades), não acarretaram danos significativos no crescimento normal dos animais.

As médias gerais, para o consumo alimentar e a conversão alimentar, durante todo período experimental, não apresentaram diferenças significativas. Em geral, esses coeficientes mantiveram-se constantes, provavelmente porque a consistência, aparência e palatabilidade das dietas não constituíram fatores de grandes adversidades entre as formas de carboidrato consumidas pelos animais neste trabalho.

Para a eficiência alimentar, nota-se que não houve diferenças significativas entre os tratamentos.
Especificamente na Fase 3, logo após os animais serem submetidos ao exercício exaustivo, a forma complexa apresentou melhora na eficiência alimentar, fato não verificado para a forma simples; isso pode ter levado à possível melhora na absorção alimentar e conseqüente manutenção do peso corporal, fato que pode ser confirmado observando-se as médias de peso corporal. Isso está relacionado a um provável aumento no metabolismo gerado pela atividade física.

\section{Glicogênio muscular e hepático}

Na Figura 1 encontra-se o conteúdo de glicogênio entre as fases experimentais. Nota-se que o programa treinamento (Fase 2), com duração de 30 dias, foi eficaz para os tecidos musculares e a supercompensação (Fase 3) foi altamente eficaz para os tecidos hepáticos. Ambos os procedimentos acarretaram mudanças nos conteúdos teciduais de glicogênio, sendo essas mudanças significativas.

As respostas fisiológicas mais significativas ocorreram no tecido hepático referentes à supercompensação Fase 3. Durante o experimento, os músculos Sóleo e Gastrocnêmio apresentaram valores crescentes nos teores de glicogênio e os tecidos hepáticos apresentaram teores de glicogênio superiores ao do tecido muscular, concordando com as informações de Harper et al. (1990) e Guyton \& Hall (1996). Segundo esses autores, o tecido hepático retém quantidade glicogênio superior ao do tecido muscular.

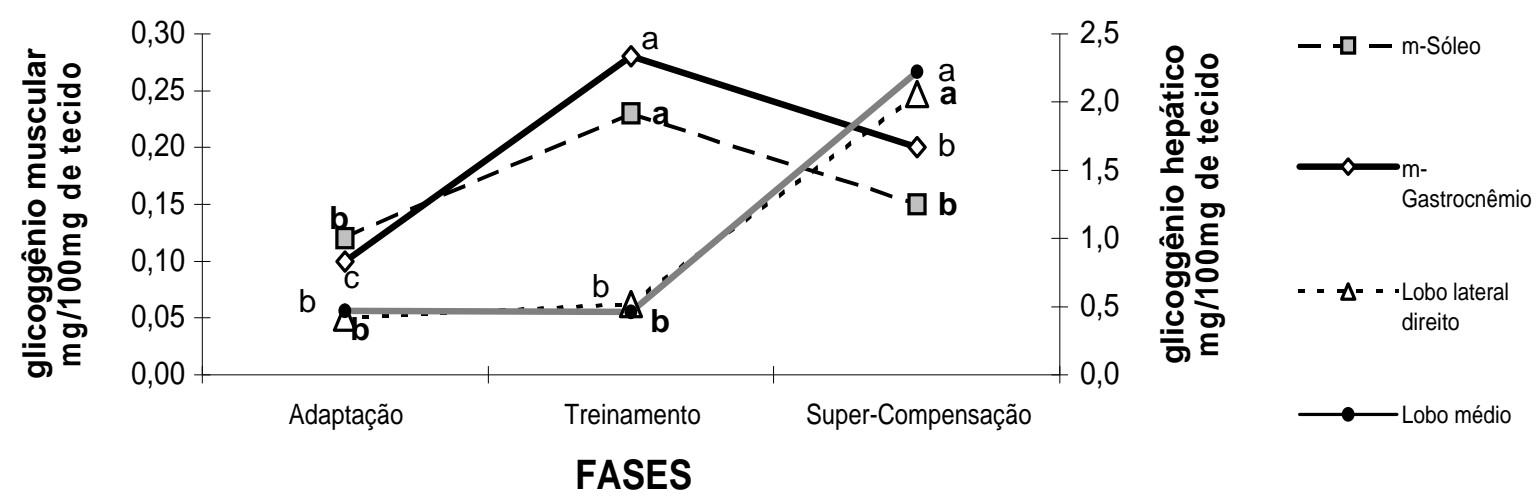

FIGURA 1 - Valores médios do conteúdo de glicogênio (mg/100mg de tecido) nos músculos Sóleo e Gastrocnêmio e nos lóbulos hepáticos Lateral direito e Médio, em função das fases. Letras iguais na mesma linha não diferem pelo teste de Tukey (5\%). 
Quantidades elevadas de glicogênio em animais treinados são apresentadas por Bergstrom \& Hultman (1966), Sherman (1983) e Zachwieja et al. (1991). Esses pesquisadores informam que as maiores taxas de repleção dos depósitos de glicogênio ocorrem nos tecidos depletados de seus estoques.

Os valores de glicogênio muscular apresentaramse similares aos verificados por Gobatto (1993). Porém, para o tecido hepático, os valores do presente estudo foram até cinco vezes mais elevados que os encontrados por esse autor (0,4 mg de glicogênio/100 mg de tecido), isso para fase de supercompensação, valendo salientar que o referido autor não realizou a fase de supercompensação de glicogênio.

Para a maioria dos tecidos estudados: grupo muscular (músculo Sóleo) e ambos lóbulos os hepáticos (Latereal-direito e médio), as duas formas de carboidrato ingeridas pelos animais não apresentam diferenças estatísticas. Resposta semelhante para as formas de carboidratos foi verificada por Roberts et al. (1988), embora esse estudo tenha sido realizado com humanos. Diferenças nos tecidos foram detectadas em relação às $\mathrm{Fa}$ ses, sendo as maiores médias encontradas nos tecidos musculares na Fase 2 (média de $0,25 \mathrm{mg}$ de glicogênio/100 mg de tecido); já nos tecidos hepáticos, as maiores médias foram registradas na Fase 3 ( média de 2,11 mg de glicogênio/100 mg de tecido).

Somente no músculo Gastrocnêmio verificaramse diferenças significativas, quando os animais consumiram dieta na forma de carboidrato complexo nas Fa- ses 2 e 3, apresentando valores mais expressivos no conteúdo de glicogênio tecidual. $\mathrm{O}$ carboidrato na forma complexa na Fase 2 teve média estatisticamente superior $(0,37 \mathrm{mg}$ de glicogênio/100 $\mathrm{mg}$ de tecido), comparada à obtida pela forma simples $(0,19 \mathrm{mg}$ de glicogênio/100 mg de tecido). Na Fase 3, a forma complexa (0,23 mg de glicogênio/100 $\mathrm{mg}$ de tecido) continuou mantendo média superior no armazenamento de glicogênio tecidual, comparado à forma simples $(0,16 \mathrm{mg}$ de glicogênio /100 mg de tecido). Fato semelhante ao apresentado por Costill et al. (1981).

Na Figura 2 encontram-se os valores médios do conteúdo de glicogênio (mg/100mg de tecido) nos tecidos musculares e hepáticos e seus comportamentos diante da repleção glicogênica em função do tempo (horas).

Para todos tecidos, foi verificado um pico glicogênico após doze horas do exercício extenuante, independente da forma de carboidrato consumida. As formas de carboidratos não apresentaram diferenças significativas, para a maioria dos tecidos, em que somente o tempo (horas) mostrou-se significativo. Na Figura 2 pode se verificar nitidamente um comportamento similar e quase padrão em todos os tecidos durante as horas de repleção, uma vez que os picos de absorção glicogênica foram coincidentes (Figura 3).

A Figura 3 apresenta os valores médios do conteúdo de glicogênio $(\mathrm{mg} / 100 \mathrm{mg}$ de tecido) de todos os tecidos em função do tempo, nas horas prédeterminadas $(0,6,12,24,48,72 \mathrm{~h})$.

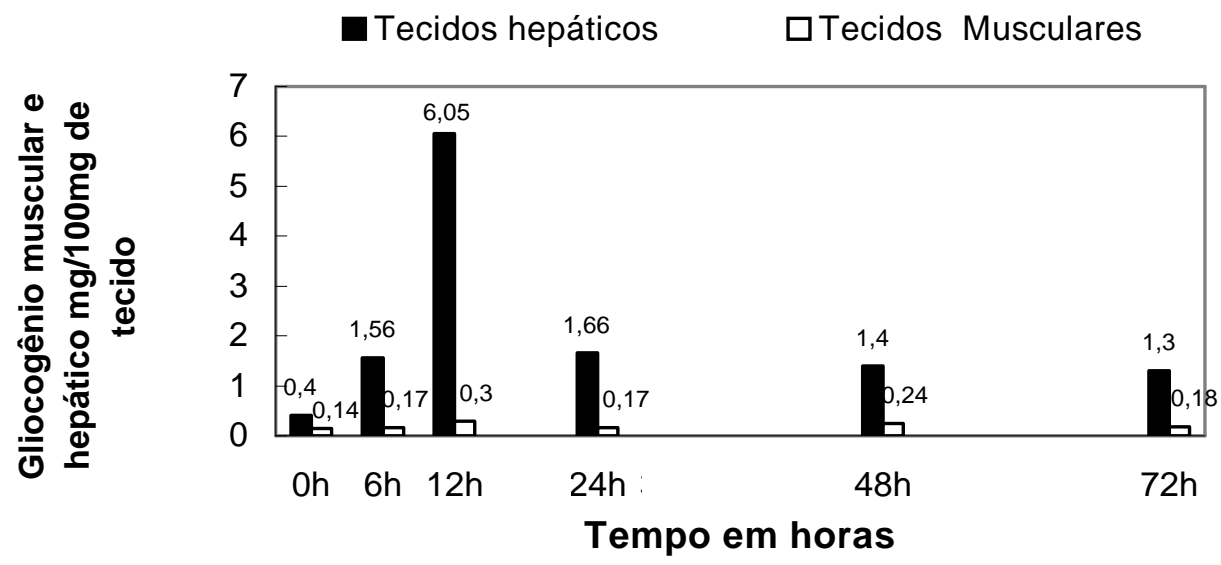

FIGURA 2 - Valores médios do conteúdo de glicogênio (mg/100mg de tecido), em função dos tecidos e diante do tempo (horas).

De acordo com Roberts et al. (1988), no que diz respeito à repleção de glicogênio, não existem diferenças entre as formas simples ou complexas de carboidra- tos. Esse fato se apresenta em concordância com a maioria dos resultados obtidos neste trabalho. 
Somente o músculo Gastrocnêmio apresentou diferenças significativas entre as formas de carboidrato consumidas. Na Figura 4 apresentam-se os valores médios do conteúdo de glicogênio no músculo Gastrocnêmio em função do tempo e das formas de carboidrato consumidas e seus comportamentos durante a repleção glicogênica.

O músculo Gastrocnêmio apresentou diferenças significativas entre as formas de carboidrato consumidas. A forma complexa de carboidrato nesse tecido apresentou-se mais eficiente que a forma simples, no decorrer do tempo, apresentando uma repleção mais pre- coce e maior acúmulo de glicogênio; isso para todos os pontos pré-estabelecidos para a determinação da repleção glicogênica. Vale salientar que, nesse grupo muscular, foram verificados dois picos de maior repleção glicogênica: o maior, às 12 horas, seguindo o padrão e similariedade dos outros tecidos estudados, e um segundo de proporção menor, às 48 horas. Esses resultados discordam do estudo de Kiens et al. (1990), na parte em que os referidos autores afirmam que o consumo de carboidrato na forma simples (sacarose) resultou em maior repleção glicogênica nas primeiras seis horas pós exercício.

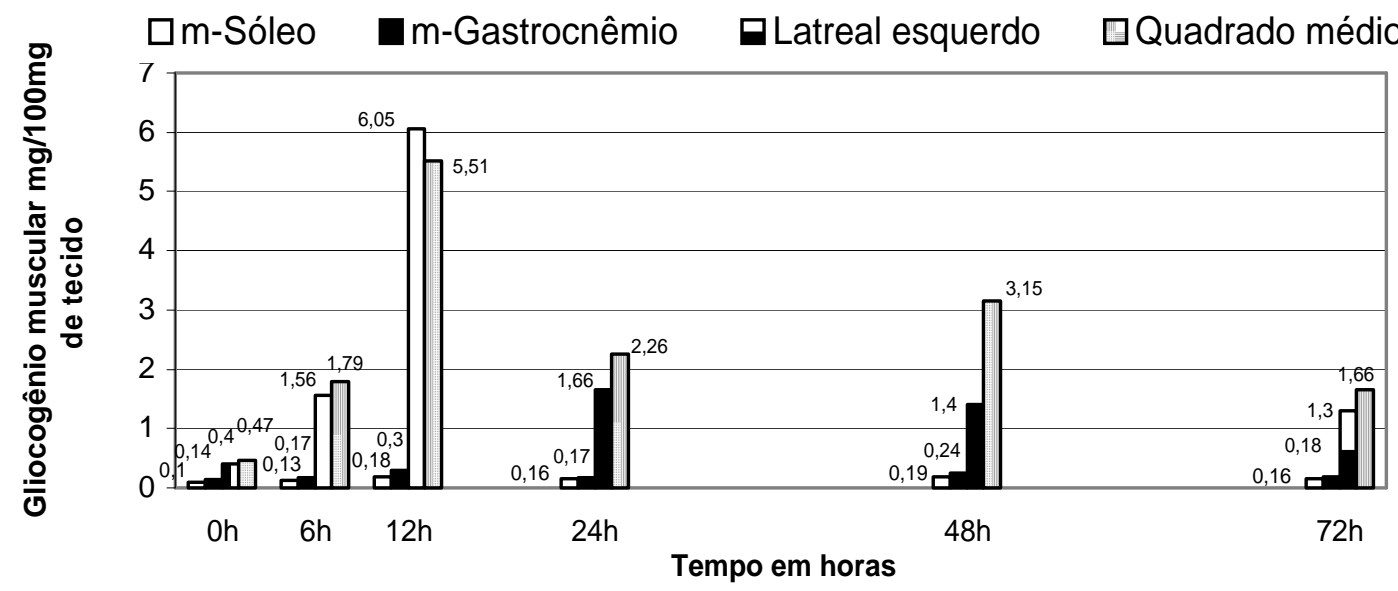

FIGURA 3 - Valores médios do conteúdo de glicogênio (mg/100 mg de tecido) de todos os tecidos em função do tempo, em todos horários pré-estabelecidos para quantificação.

\section{Conteúdo de Glicogênio no Músculo Gastrocnêmio}

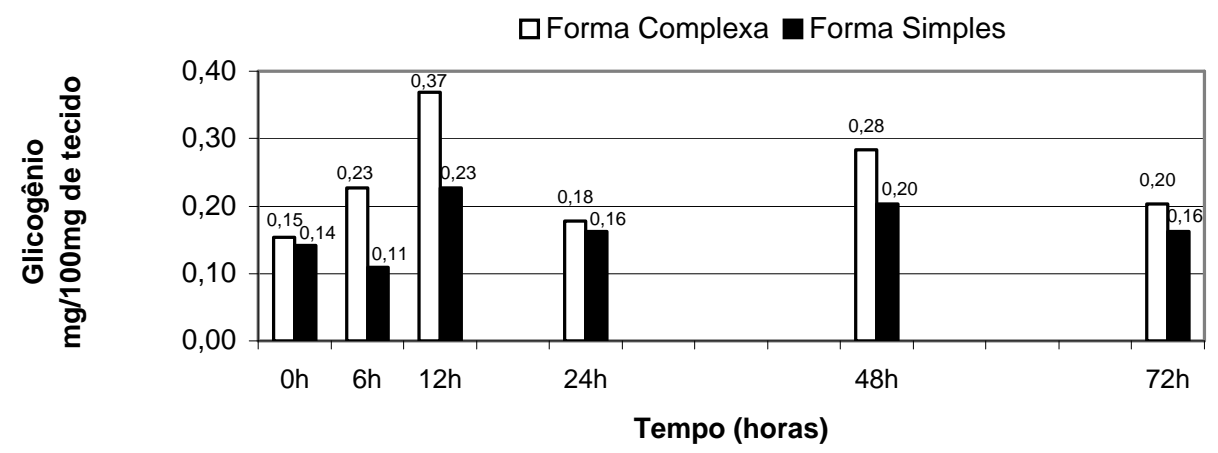

FIGURA 4 - Valores médios do conteúdo de glicogênio (mg/100 mg de tecido) no músculo Gastrocnêmio em função do tempo e das formas de carboidrato consumidas durante a repleção glicogênica. 
Observando o ocorrido em todos os tecidos, fica claro que o consumo de carboidrato na forma simples (sacarose) ou carboidrato na forma complexa (amido de milho), diante do comportamento da curva de repleção de glicogênio, nota-se que esta quase não apresenta diferenças significativas. O estudo de Kiens et al. (1990) concorda em parte com os resultados deste trabalho, já que os referidos autores afirmam que, vinte horas após o exercício, as concentrações de glicogênio apresentaram-se semelhantes, independentes da forma de carboidrato consumida.

Os resultados aqui encontrados concordam com as afirmativas de Costill et al. (1981), os quais propõem haver normalização dos níveis glicogênicos teciduais dentro das 24 horas seguintes à atividade, se a ingestão de carboidratos for suficiente. Concordam ainda, em parte, quando os mesmos autores afirmam que o consumo de uma dieta rica em carboidratos na forma complexa é mais eficiente no segundo dia de recuperação do conteúdo de glicogênio, já que tal fato foi verificado no músculo Gastrocnêmio. Quando a forma de carboidrato consumida era a forma complexa, verificou-se diferença significativa nos teores de glicogênio somente no músculo Gastrocnêmio. Foi considerada, portanto, a forma complexa de carboidrato melhor na repleção desse tecido.

Ivy (1991) indica que a repleção glicogênica parece ser mais rápida nas duas primeiras horas após o exercício, fato que não pode ser verificado neste trabalho, porque a primeira quantificação neste estudo ocorreu após as seis primeiras horas.

Pelo fato de o maior pico de repleção de glicogênio ter sido atingido 12 horas após o exercício extenuante, em todos tecidos estudados, é importante ressaltar que, para continuação das atividades ou esforços desse tipo, é necessária a ingestão de refeições ricas em carboidratos, independente das formas. Também é necessário que se aguarde pelo menos 12 horas pósexercício extenuante, de forma que os depósitos de gli- cogênio atinjam a maior concentração possível e, assim, produzam o aumento de rendimento físico. Conforme Wolinsky \& Hickson Júnior (1996), é aconselhável não ultrapassar o limite de duas a três vezes o programa de supercompensação de glicogênio ao mês, a fím de se manter a integridade corporal.

\section{Glicose sérica}

Na Tabela 3 apresentam-se os valores médios do conteúdo de glicose plasmático $(\mathrm{mg} / \mathrm{dL})$ em função das três Fases experimentais e das formas de carboidrato.

Pela Tabela 3, nota-se que houve diferença significativa nos valores médios de glicose plasmática entre as Fases, sendo a maior média encontrada na Fase 3. Os níveis glicêmicos estiveram na faixa de 78,22 mg/dL em médias gerais para a forma complexa e ligeiramente acima para a forma simples. O fato de as dietas terem sido preparadas com alto teor de carboidratos foi fundamental para na manutenção da glicemia plasmática. Esse fato está de acordo com o estudo realizado por Holloszy (1990), que afirma que as reduções de glicose plasmáticas são menos prováveis após ingestão de dietas com elevado teor de carboidratos.

Os níveis glicêmicos mais baixos em animais treinados estão de acordo com as explicações de Bonen et al. (1990). Esses autores afirmam que a contração por si só parece aumentar a captação de glicose para as fibras musculares, reduzindo assim a glicemia plasmática, fato que provavelmente ocorreu para ambos os tratamentos aqui estudados em função do treinamento realizado.

A Tabela 4 apresenta os valores das médias glicêmicas $(\mathrm{mg} / \mathrm{dL})$ em função das formas de carboidrato na Fase 2, dosados antes e após período de jejum de aproximadamente nove horas.

TABELA 3 - Valores médios do conteúdo de glicose plasmático (mg/dL), em função três Fases experimentais (Fase 1,2 e 3 ) e das formas de carboidrato.

\begin{tabular}{ccccc}
\hline Forma de CHO & Fase 1 & Fase 2 & Fase 3 & Média geral \\
\hline Simples & 74,1 & 70,8 & 84,5 & $78,5^{\text {a }}$ \\
Complexa & 64,6 & 67,7 & 89,0 & $78,2^{\text {a }}$ \\
\hline Média geral & $69,35^{\mathrm{B}}$ & $69,28^{\mathrm{B}}$ & $86,79^{\mathrm{A}}$ & 78,37 \\
\hline
\end{tabular}

Letras minúsculas na coluna representam as formas de CHO e letras maiúsculas na linha representam as fases. Valores seguidos de letras iguais não diferem pelo teste de Tukey (5\%). 
A Tabela 4 apresenta o teor médio de glicose plasmática verificado nos animais ao consumirem as duas formas de carboidratos na Fase 2, em que a glicose foi dosada antes e pós período de jejum de aproximadamente nove horas, em que verificou-se diferença significativa $(\mathrm{p} \leq 0,05)$ para o tratamento em que se consumiu a forma simples de carboidrato (sacarose). Podese observar também que a forma complexa de carboidrato sustentou melhor as condições glicêmicas, após um jejum prolongado, indicando que os maiores níveis glicêmicos foram apresentados pela forma complexa (baixa glicêmica de apenas 7,5 mg/dL). Isso concorda com as afirmações de Holloszy (1990), para quem as reduções plasmáticas são menos prováveis após ingestão de dietas com elevados teores de carboidratos.

De acordo a Figura 5, houve diferença significativa entre as formas de carboidrato e tempo. Nas pri- meiras doze horas pós-exercício extenuante (evento), quando se consumiu a forma de carboidrato simples, resultou em níveis glicêmicos mais elevados. Mas, nas horas seguintes, esses níveis glicêmicos foram inferiores aos da forma complexa, apresentando algumas oscilações. Já a forma complexa de carboidrato após as doze horas teve melhor estabilidade e aumento progressivo no decorrer do tempo.

Os valores de glicose sérica encontrados neste trabalho concordam em parte com os relatos de Coleman (1991), o qual afirma que carboidratos complexos forneceram níveis de glicose e insulina mais baixos; isso porque durante as 12 horas no pós-evento verificaram-se níveis de glicose mais baixos. Mas, nas horas consecutivas houve predominância do grupo que consumiu carboidratos na forma complexa em apresentar índices de glicose mais elevados.

TABELA 4 - Valores médios da glicemia plasmática (mg/dL) em função das formas de carboidrato na Fase 2, dosados antes e após o período de jejum de nove horas.

\begin{tabular}{ccccc}
\hline \multirow{2}{*}{ Forma de CHO } & $\begin{array}{c}\text { Antes do } \\
\text { jejum }(9 h)\end{array}$ & $\begin{array}{c}\text { Depois do } \\
\text { Jejum }(\mathbf{9 h})\end{array}$ & $\begin{array}{c}\text { Média } \\
\text { Geral }\end{array}$ & $\begin{array}{c}\text { Baixa } \\
\text { glicêmica }\end{array}$ \\
\hline Simples & $78,75^{\mathrm{aA}}$ & $62,88^{\mathrm{aB}}$ & $70,81^{\text {a }}$ & 15,87 \\
Complexa & $71,50^{\mathrm{aA}}$ & $64,00^{\mathrm{aA}}$ & $67,75^{\text {a }}$ & 7,5 \\
\hline Média geral & $75,13^{\mathrm{A}}$ & $63,44^{\mathrm{B}}$ & 69,28 & - \\
\hline
\end{tabular}

Letras minúsculas nas colunas representam as formas de CHO e letras maiúsculas nas linhas representam o tempo. Valores seguidos de letras iguais não diferem pelo teste de Tukey (5\%).

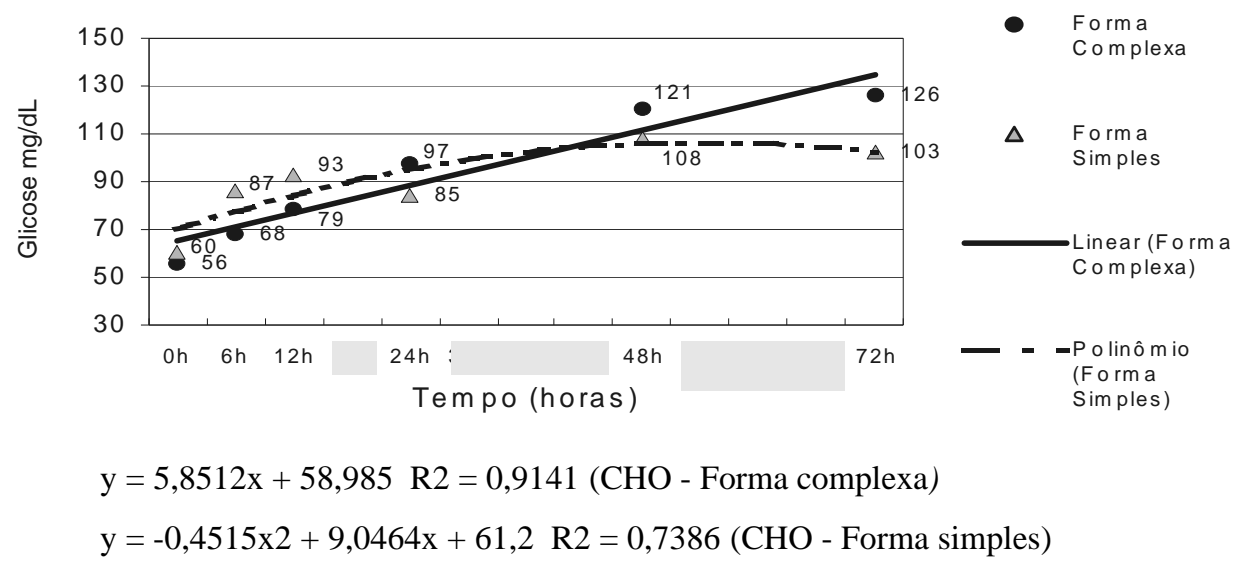

FIGURA 5 - Valores médios do conteúdo de glicose plasmática (mg/dL), em função das horas e das formas de carboidrato consumidas.

Ciênc. agrotec., Lavras. V.27, n.3, p.605-617, maio/jun., 2003 
Segundo Blom et al. (1987), a atividade que foi realizada neste trabalho na parte denominada "evento" produz danos e dor muscular. Friedman et al. (1991) afirmam que os decréscimos na disponibilidade de glicose para ressíntese de glicogênio podem ser atribuídos a danos no sarcolema, com subseqüente interferência no transporte de glicose. Todos esses interferentes proporcionam oxidação significativamente maior pelas células leucocitárias, produzindo, assim, um fator que estimula a oxidação da glicose pelas células circunvizinhas, sendo de extrema importância que os níveis glicêmicos sejam reestabelecidos no menor tempo possível. Tal fato provavelmente deve ter corrido neste trabalho, em que os níveis glicêmicos atingiram quantidades próximas ou superiores às Fases 1 e 2, 6 horas após o evento, apresentando melhores resultados quando se ingeriu a forma complexa de carboidrato.

\section{Lipídios totais}

Na Tabela 5 encontram-se os valores médios dos lipídios totais séricos $(\mathrm{mg} / \mathrm{dL})$ de ratos Wistar treinados em função das formas de carboidrato e de sua interação com as Fases experimentais.

De acordo com a Tabela 5, foi verificada diferença significativa entre as Fases experimentais, e quando os animais consumiram a forma complexa de carboidrato, esses apresentaram as maiores médias em termos de lipídios totais, principalmente na Fase 2. Isso se deve ao fato de que o condicionamento físico provavelmente acarretou mudanças morfo-fisiológicas, aumentando o número e/ou tamanho de células especializadas no metabolismo oxidativo. Assim, possivelmente, melhorou o processo de enzimas responsáveis pelo transporte das gorduras para locais específicos onde podem ser metabolizadas e utilizadas de forma mais eficiente, tornado-se uma fonte secundária de energia e um agente poupador de reservas de carboidratos.
Os valores para lipídios totais séricos encontrados neste trabalho estão também próximos aos de Jong (1996), a qual trabalhou com ratos alimentados com dietas normo e hiperlipídicas e encontrou valores para os lipídios séricos da ordem de $467 \mathrm{mg} / \mathrm{dL} \pm 37$, para animais do grupo controle.

Os resultados deste trabalho concordam com as afirmativas de Holloszy (1988), o qual informa que o treinamento físico provoca um aumento adaptativo na utilização das reservas de gorduras. No músculo esquelético, essa oxidação parece inibir a captação de glicose, glicólise e glicogenólise, fato que pode ser comprovado ao se comparar os dados de glicose e lipídios totais do presente trabalho, principalmente na Fase 2. Na Fase 2, foram encontrados os maiores teores de lipídios e baixa glicemia. Essa situação acarreta simultaneamente uma economia das reservas de glicogênio, o que é fundamental para prolongar o exercício ou, pelo menos, retardar à chegada à exaustão.

A Figura 6 apresenta os valores médios do conteúdo de lipídios totais séricos $(\mathrm{mg} / \mathrm{dL})$, em função do tempo (horas), na Fase 3.

Para os valores de lipídios totais séricos referentes à Fase 3, verificou-se diferença significativa. Com o avançar das horas, observa-se o aumento gradual dos teores dos lipídios totais, independente da forma de CHO consumida pelos animais. De acordo com a Figura 6, espera-se um aumento médio de aproximadamente $3,8 \mathrm{mg} / \mathrm{dL}$ nos teores de lipídios totais para cada acréscimo de uma hora no tempo. Isso pode ser justificado biologicamente, uma vez que com o afastar da atividade física intensa, o organismo volte à calma, normalizando seu metabolismo, em que o mesmo, em estado de repouso, faz um maior uso das reservas energéticas provenientes dos lipídios para a produção de energia. Exceção é feita para órgão que tem necessidade exclusiva de glicose.

TABELA 5 - Valores médios dos lipídios totais séricos (mg/dL) no soro de ratos Wistar treinados em função das formas de carboidrato e das Fases experimentais.

\begin{tabular}{ccccc}
\hline Forma de CHO & Fase 1 & Fase 2 & Fase 3 & Média geral \\
\hline Simples & 445,2 & 463,7 & 330,2 & $383,0^{\mathrm{a}}$ \\
Complexa & $368,4^{\mathrm{a}}$ & $640,2^{\mathrm{a}}$ & 360,7 & $415,8^{\mathrm{a}}$ \\
\hline Média geral & $406,8^{\mathrm{B}}$ & $552,0^{\mathrm{A}}$ & $345,5^{\mathrm{B}}$ & 399,4 \\
\hline
\end{tabular}

Letras minúsculas na coluna representam as formas de CHO e letras maiúsculas na linha representam as Fases. Valores seguidos de letras iguais não diferem pelo teste de Tukey (5\%). 


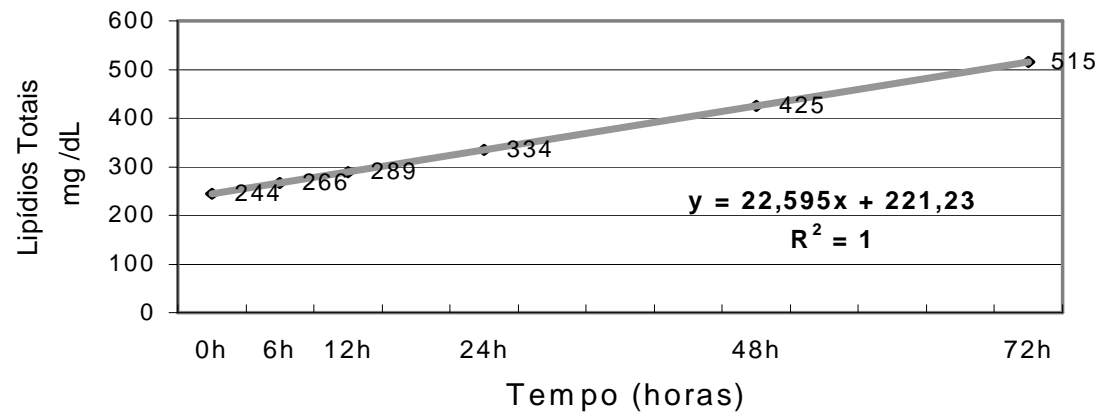

FIGURA 6 - Representação gráfica e equação de regressão para conteúdo de lipídios totais (mg/dL), em função do tempo (horas) na Fase 3.

\section{CONCLUSÕES}

O treinamento físico para ratos elevou os níveis teciduais de glicogênio, e as formas de $\mathrm{CHO}$ simples (sacarose) ou complexa (amido de milho) não interferiram na maioria dos parâmetros bioquímicos analisados (glicogênio tecidual, glicose plasmática e lipídios totais séricos). Porém, a forma complexa, quando comparada à forma simples, não proporciona redução nos níveis de glicose sérica no pós-jejum de nove horas. Além do que, a forma complexa mostrou-se mais eficaz diante da média de peso corporal.

Apenas no músculo Gastrocnêmio, a forma complexa de $\mathrm{CHO}$ resultou em maior índice de repleção glicogênica, sendo mais elevado nos períodos de 6,12 e 48 horas pós-exercício extenuante, quando comparado à forma simples de $\mathrm{CHO}$ (sacarose).

A supercompensação de glicogênio promoveu armazenamento de glicogênio superior nos tecidos hepáticos dos ratos, quando comparados ao tecido muscular.

Após exercício extenuante, a maior repleção de glicogênio em todos tecidos ocorreu com 12 horas, consumindo dietas com $\mathrm{CHO}$ simples ou complexos e observou-se o aumento gradual dos teores dos lipídios totais a cada hora sucessiva ao exercício, independente da forma de CHO.

\section{REFERÊNCIAS BIBLIOGRÁFICAS}

BERGSTROM, J.; HULTMAN, E. Muscle glycogen synthesis after exercise an enhancing factor localized to the muscle cells in man. Nature, London, v. 210, n. 5033, p. 309-310, Apr. 1966.

BERGSTROM, J.; HERMANSEN, L.; HULTMAN, E.; SALTIN, B. Diet, muscle glycogen and physical per- formance. Acta Physiology Scandinavian, Oxford, v. 71, p. 140, 1967.

BLOM, P. C. S.; COSTILL, D. L.; VOLLESTAD, N. K. Exhaustive running: inappropriate as a stimulus of muscle glycogen supercompensation. Medicine Science in Sports and Exercise, Madison, v. 19, n. 4, p. 398, July/Aug. 1987.

BONEN, A.; McDERRNOTT, J. C.; TAN, M. H. Glucose transport in skeletal muscle. In: TAYLOR, A. W.; GOLINICK, P. D.; GREEN, H. J.; IANUZZO, C. D.; NOBLE, E. G.; MÉTIVIER, G.; SUTTON, J. R. Biochemistry of Exercise VII, Champaign: Human Kinetics Books, 1990. 295 p.

COGGAN, A. R.; COYLE, E. F. Carbohydrate ingestion during prolonged exercise: effects on metabolism and performance. Exercise Sport Science Review, Madison, v. 19, n. 1, Jan./Feb. 1991.

COYLE, E. F. Carbohydrate supplementation during exercise. Journal Nutrition, Bethesda, v. 122, n. 4, p. 788-888, Apr. 1992.

COLEMAN, E. Carbohydrates: the master fuel. In: BERNING, J. R.; STEEN, S. N. Sports nutrition for the 90s. Caithersburg: Aspen, 1991. cap. 3.

COSTILL, D. L.; SHERMAN, W. M.; FINK, W. J.; MARESH, C.; WITTEN, M.; MILLER, J. M. The role of dietary carbohydrates in muscle glycogen resynthesis after strenuous running. Amerincn Journal of Clinical Nutrition, New York, v. 34, n. 11, p. 1831, Nov. 1981.

DUBOIS, M. K. A.; GILLES, H. J. K.; REBERS, P. A.; SMITH, F. Colorimetric method for determination of sugars and related substances. Analytical chemistry, Minnesota, v. 28, n. 3, p. 350-355, Mar. 1956. 
FERREIRA, D. F. SISVAR: sitema de análise de variância: versão 4.0. Lavras: UFLA, 2000.

FRIEDMAN, J. E.; NEUFER, P. D.; DOHM, G. L. Regulation of glycogen resynthesis following exercise. Sports Medicine, Auckland, v. 11, n. 3, p. 232, Mar. 1991.

GOBATTO, A. C. Alterações metabólicas decorrentes do treinamento físico em ratos previamente desnutridos e recuperados. 1993. 122 f. Dissertação (Mestrado em Ciências Fisiológicas) - Universidade Estadual de Campinas, Campinas.

GOLLNICK, P. D.; SALTIN, B. Fuel for muscular exercise: role of fat. In: HORTON, E. S.; TERJUNG, R. L. Exercise, nutrition and energy metabolism. New York: Macmillan, 1988. cap 5.

GOMES, F. P. Curso de estatística experimental. 13. ed. Piracicaba: Nobel, 1990. 468 p.

GUYTON, A. C.; HALL, J. E. Tratado de fisiologia médica. Rio de Janeiro: Guanabara Koogan, 1996. 1014 p.

HARPER, H. A.; RODWELL, V. W.; MAVES, P. A. Manual de química fisiológica. 5. ed. São Paulo: Atheneu, 1990.

HENRY, R. J. Clinical chemistry principles and techiniques. 2. ed. Hargeston: Harper e How, 1974.

HOLLOSZY, J. O. Utilization of fatty acids during exercise. In: TAYLOR, A. W.; GOLLNICK, P. D.; CREEN, H. J.; IANUZZO, C. D.; NOBLE, E. G.; MÉTIVIER, G.; SUTTON, J. R. Biochemistry of exercise VII. Champaign: Human Kinetics Books, 1990. 319 p.

HOLLOSZY, J. O. Metabolic consequences of endurance exercise training. In: HORTON, E. S.; TERJUNG, R. L. Exercise, nutrition and energy metabolism. New York: Macmillan, 1988. cap. 8.

IVY, J. L. Muscle glycogen synthesis before and after exercise. Sports Medicine, Auckland, v. 11, n. 6, 1991.

JONG, E. V. de. Influência de dietas normo e hiperlipídicas sobre o perfil nutricional, parâmetros bioquímicos séricos e estruturais do fígado de ratos Wistar. 1996. 140 f. Tese (Doutorado em Ciências da Nutrição) - Universidade Estadual de Campinas, Campinas.
KIENS, B.; RABEN, A. B.; VALEUR, A. K.; RICHTER, E. A. Benefit of dietary simple carbohydrates on the early postexercise muscle glycogen repletion in male athletes. Medicine Science in Sports and Exercise, Madison, v. 22, n. 2, p. S88, Feb. 1990.

MAHAN, L. K.; ESCOT-STUMP, S. Krause: alimentos, nutrição e dietoterapia. 9. ed. São Paulo: Rocca, 1998. $1179 \mathrm{p}$.

REEVES, P. G.; NIELSEN, F. H.; FAHEY, G. C. AIN93 purified diets for laboratory rodents: final report of the American Institute of Nutrition ad hoc writing committee on the reformulation of the AIN-96 rodent diet. The Journal of Nutrition, Bethesda, v. 123, n. 11, p. 1939-1951, Nov. 1993.

ROBERTS, K. M.; NOBEL, E. G.; HAYDEN, D. B.; TAYLOR, A. W. Simple and complex carbohydrate rich diets and muscle glycogen content of marathon runners. European Journal of Applied Physiology, Heidelberg, v. 57, n. 1, p. 70, Jan. 1988.

SAS INSTITUTE. SAS/ETF: user's guide: version 6 . 2. ed. New York: Carry, 1993.

SHERMAN, W. H. Carbohydrates, muscle glycogen and muscle glycogen supercompensation. In: WILLIAMS, M. H. Ergogenic aids in sports. Champaign: Human Kinetics, 1983. cap. 3.

SHERMAN, W. H.; COSTILL, D. L. The maraton: dietary manipulation to optimize performance. American Journal Sports Medicine, Baltimore, v. 12, n. 1, p. 4451, Jan./Feb. 1984.

WOLINSK, I.; HICKSON JÚNIOR, J. F. Nutrição no exercício e no esporte. 2. ed. São Paulo: Roca, 1996. 548 p.

ZAKHAROV, A. Ciência do treinamento desportivo. Rio de Janeiro: Grupo Palestra Sport, 1992. 338 p.

ZACHWIEJA, J. J.; COSTILL, D. L.; PASCOE, D. D.; ROBERGTS, R. A.; FINK, W. J. Influence of muscle glycogen depletion on the rate of resynthesis. Medicine Science in Sports and Exercise, Madison, v. 23, n. 1, p. 44, Jan. 1991. 